\title{
Induction of apoptosis in MCF-7 human breast cancer cells by Khz (fusion of Ganoderma lucidum and Polyporus umbellatus mycelium)
}

\author{
TAE HWAN KIM ${ }^{1}$, JU SUNG KIM ${ }^{2}$, ZOO HAYE KIM ${ }^{3}$, REN BIN HUANG ${ }^{4}$, \\ YOUNG LYE CHAE ${ }^{5}$ and REN SHENG WANG ${ }^{1}$
}

\begin{abstract}
${ }^{1}$ Department of Radiotherapy, The First Affiliated Hospital, Guangxi Medical University, Nanning, Guangxi 530021;
${ }^{2}$ Department of Clinical Medicine, Harbin Medical University, Harbin, Heilongjiang 150000, P.R. China;

${ }^{3}$ Department of Information Engineering, Graduate School of Information Science, Nagoya University, Nagoya, Aichi 452-0813, Japan; ${ }^{4}$ Department of Pharmacology, Guangxi Medical University, Nanning, Guangxi 530021, P.R. China;

${ }^{5}$ Pharmacology and Drug Development, Korean Institute of Science and Management Career College,
\end{abstract} Seoul 158-867, Republic of Korea

Received December 8, 2014; Accepted September 1, 2015

DOI: $10.3892 / \mathrm{mmr} .2015 .4655$

\begin{abstract}
Khz (fusion of Ganoderma lucidum and Polyporus umbellatus), isolated from the mycelia of G. lucidum and $P$. umbellatus, exerts anti-proliferative effects against malignant cells; however, its activity against human breast cancer cells remains to be elucidated. In the present study, cell proliferation was assessed using a 3-(4,5-dimethylthiazol-2-yl)-2,5-diphenyltetrazolium bromide assay, and poptosis was examined using annexin V-propidium iodide staining and flow cytometry. The activation of caspases 7,8 and 9 were detected in the Khz-treated cells using western blotting. The results demonstrated that $\mathrm{Khz}$ increased the intracellular calcium concentration and induced the production of reactive oxygen species in $\mathrm{MCF}-7$ breast cancer cells, as determined using flow cytometry. The results also demonstrated that $\mathrm{Khz}$ inhibited cell proliferation and induced apoptosis in the MCF-7 cells. In addition, the mechanism by which Khz induces apoptosis in cancer cells was investigated. Khz induced apoptosis preferentially in transformed cells, with a minimal effect on non-transformed cells, suggesting its potential as an anticancer therapeutic agent. Oxidative stress is associated with apoptotic and non-apoptotic cell death, although pro-oxidative conditions are not a pre-requisite for apoptosis. Assessment of the activation status of caspases 7, 8 and 9 revealed that the levels of cleaved caspases were significantly increased in the cells treated with Khz. It is widely
\end{abstract}

Correspondence to: Dr Ren Sheng Wang, Department of Radiotherapy, The First Affiliated Hospital, Guangxi Medical University, 22 Guangxi Double-Support Road, Nanning, Guangxi 530021, P.R. China

E-mail: 13807806008@163.com

Key words: Khz, fusion, Ganoderma lucidum, apoptosis, reactive oxygen species accepted that calcium signaling is important in apoptosis, and the present study observed an increase in $\left[\mathrm{Ca}^{2+}\right]_{\mathrm{i}}$ in response to Khz treatment. The anti-proliferative and pro-apoptotic effects of Khz suggest that this extract may be developed as a potential anticancer agent.

\section{Introduction}

Ganoderma lucidum (Fr.) Karst, of the family Polyporaceae, has been used as a Traditional medicine for several thousand years in China, Japan and other countries. Evidence has accumulated concerning the medicinal use of Ganoderma to treat various diseases, including cancer and immunological disorders, and its biotechnological utilization has become popular (1-5). The mixture of triterpenoids naturally occurring in $G$. lucidum inhibits the proliferation of human and mouse carcinoma cell lines (6). Studies have reported that the cytotoxicity mediated by triterpene-enriched extracts of G. tsugae in MCF-7 human breast cancer, prostate cancer and PC-3 cells occurs via apoptosis and cell-cycle arrest (7-9). Another study demonstrated that apoptosis induced by triterpene-enriched extracts of G. lucidum occurs through the suppression of protein kinase $\mathrm{C}$, the activation of mitogen-activated protein kinases (MAPKs) and G2-phase cell-cycle arrest (10). Other suggested mechanisms include a reduction in intracellular calcium levels, the induction of $\mathrm{NAD}(\mathrm{P}) \mathrm{H}$ : quinone oxidoreductase in cultured hepalcic 7 murine hepatoma cells, activation of MAPKs in rat pheochromocytoma PC12 cells and stimulation of actin polymerization in bladder cancer cells in vitro. However, whether the ingredients in the extract mixtures have antagonistic or synergistic biological effects is difficult to determine. In addition, the predominant compound within the extract responsible for its bioactivity has not been identified, which further complicates the investigation of the structure-activity associations. Polyporus umbellatus, also termed Grifola umbellata is a fungus, which causes white rot in hardwoods. The sclerotia of P. umbellata, which are 
bumpy, rugged and dark brown/black, are used as a diuretic in Chinese medicine. Although the water extracts of $P$. umbellata sclerotia have diuretic effects, its methanol extracts have cytotoxic effects against human gastric cancer cells, although the active components remain to be elucidated (11). Khz is an extract mixture, produced from the mycelia of a G. lucidum (Fig. 1A) (12) and P. umbellatus (Fig. 1B) via nuclear fusion (Fig. 2A). The anticancer effect of the fusion of G. lucidum and $P$. umbellatus has been previously demonstrated (13-15). The present study aimed to investigate the mechanism underlying Khz-induced cell death in breast cancer cells. Whether Khz has the ability to inhibit cell growth and promote apoptosis in human breast cancer cells remains to be elucidated; therefore, the present study examined the effect of Khz on cell viability and on the expression of apoptosis-associated proteins in MCF-7 human breast cancer cells.

\section{Materials and methods}

Cell lines. The BEAS-2B (normal immortalized), 1799 (non-transformed), 1198 (transformed, non-tumorigenic) and 1170-I (tumorigenic) cell lines comprise an in vivo lung carcinogenesis model, which has been previously described (16-18). The MCF-7 human breast cancer cell line was purchased from American Type Culture Collection (Manassas, VA, USA) and was maintained in RPMI-1640 medium (Gibco; Thermo Fisher Scientific,Inc., Waltham,MA,USA) supplemented with $10 \%$ fetal bovine serum (GE Healthcare Life Sciences, Logan, UT, USA), $100 \mathrm{U} / \mathrm{ml}$ penicillin G sodium salt (Sigma-Aldrich, St. Louis, MO, USA), $100 \mu \mathrm{g} / \mathrm{ml}$ streptomycin sulfate (Sigma-Aldrich) and $0.25 \mu \mathrm{g} / \mathrm{ml}$ amphotericin B (Sigma-Aldrich). Unless otherwise indicated, the cells were treated with Khz dose or time dependently.

Khz (fusion of G. lucidum and P. umbellatus mycelia) extraction method.Khz (Brain Group Co.,Ltd., Seoul, Korea) was extracted first in powder form $(1 \mathrm{~kg})$ using clean water $\left(8.5\right.$ liters), at $115^{\circ} \mathrm{C}$ for $60 \mathrm{~min}$ extracts at a pressure of $1.8-2 \mathrm{~kW}$, followed by $60 \mathrm{~min}$ maturing at a hydraulic pressure of $5 \mathrm{KW}$ in order to separate Khz and debris. Subsequently, clean water (7.5 liters) was added to the residual water of the first extraction, and extraction was performed at $115^{\circ} \mathrm{C}$, for $60 \mathrm{~min}$ at a pressure of, followed by 60 min maturation and hydraulic crossroad gathering. Finally, the extracts from the first extract and the secondary extraction steps were mixed and boiled at $100^{\circ} \mathrm{C}$ for $5 \mathrm{~min}$.

3-(4,5-dimethylthiazol-2-yl)-2,5-diphenyltetrazolium bromide (MTT) assay. An MTT assay was used to determine the rate of cell survival. The MCF-7 cells were seeded into 96-well plates at a density of 2,000 cells per well, and 10/100 $\mu$ l MTT was added to each well at a final concentration of $500 \mu \mathrm{g} / \mathrm{ml}$. The mixture was incubated for $1 \mathrm{~h}$, following which the liquid in the wells was removed. Subsequently, $50 \mu$ dimethyl sulfoxide was added to each well and incubated for $10 \mathrm{~min}$, and the absorbance was recorded using a UV Max microplate reader (Molecular Devices, Palo Alto, CA, USA) at $595 \mathrm{~nm}$ (19).

Detection of apoptosis. The cells treated with Khz were washed twice in cold phosphate-buffered saline (PBS) and were stained with annexin V-fluorescein isothiocyanate (FITC)
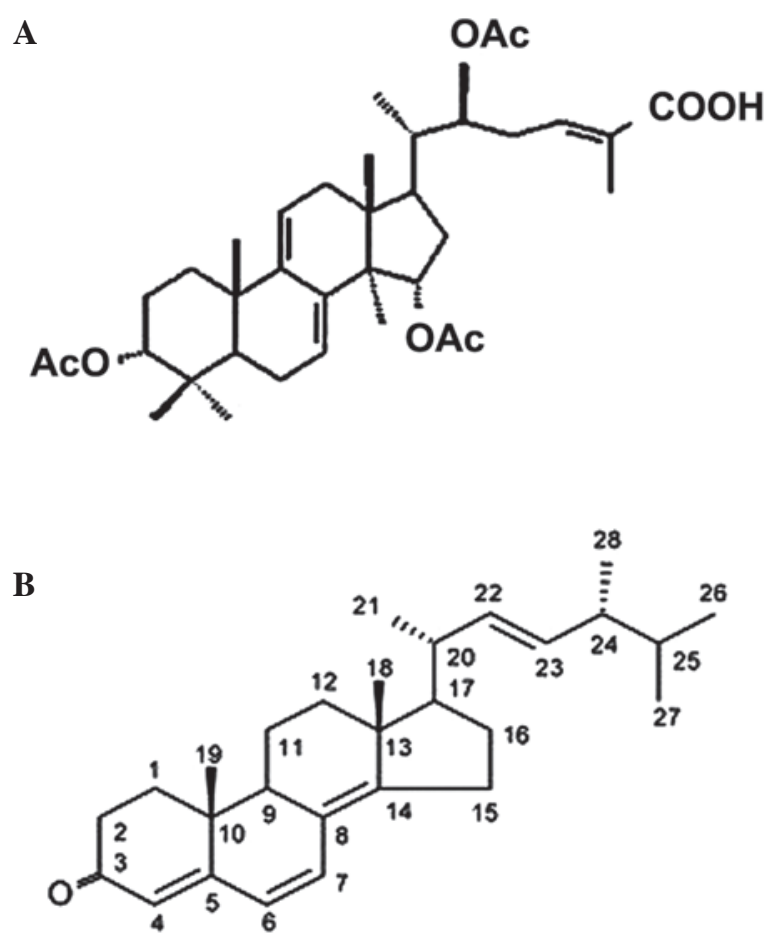

Figure 1. Chemical structure of (A) ganoderic acid T. and (B) compound isolated from the sclerotia of Polyporus umbellatus.

(cat. no. A13199, Invitrogen Life Technologies, Carlsbad, CA, USA) and propidium iodide (PI; $5 \mu \mathrm{g} / \mathrm{ml}$; Sigma-Aldrich), according to the manufacturer's instructions. Briefly, Annexin V-FITC $(5 \mu \mathrm{l})$ was added to the cells and incubated for $1 \mathrm{~h}$ at $37^{\circ} \mathrm{C}$, and the cells were then resuspended in $100 \mu \mathrm{l}$ $1 \mathrm{X}$ binding buffer containing $10 \mathrm{mM}$ HEPES, $140 \mathrm{mM} \mathrm{NaCl}$ and $2 \mathrm{mM} \mathrm{CaCl}_{2}$ (pH 7.4; Sigma-Aldrich). z-VAD-fmk was obtained from R\&D Systems (Minneapolis, MN, USA). The cells were incubated at room temperature for $15 \mathrm{~min}$, following which PI was added to the cell suspension prior to flow cytometric analysis (FACSCalibur; BD Biosciences, San Jose, CA, USA).

Detection of reactive oxygen species generation. The levels of cytoplasmic reactive oxygen species (ROS) in the cells were estimated using the oxidation-sensitive fluorescent dye, 20,70-dichlorodihydrofluorescein diacetate (H2DCF-DA; Invitrogen Life Technologies). For the DCF staining, the cells were loaded with H2DCF-DA (100 nM) for $1 \mathrm{~h}$ at $37^{\circ} \mathrm{C}$, and were then washed once with PBS, ROS levels were analyzed following Khz treatment using a flow cytometer (FACSCalibur; BD Biosciences). $\mathrm{N}$-acetyl cysteine was purchased from Sigma-Aldrich.

Detection of calcium increase. The $\mathrm{Ca}^{2+}$ levels in the MCF-7 cells were determined by staining with fluo- 4 AM. The cells, which had been treated with Khz for different durations $(0,0.5$, 1 and $2 \mathrm{~h}$ ), harvested and washed twice with PBS, and then resuspended in fluo-4 AM, followed by incubated incubation at $37^{\circ} \mathrm{C}$ for $30 \mathrm{~min}$. The changes in $\mathrm{Ca}^{2+}$ concentration were analyzed using flow cytometry. Ethylene glycol tetraacetic acid (EGTA) was purchased from Sigma-Aldrich. 

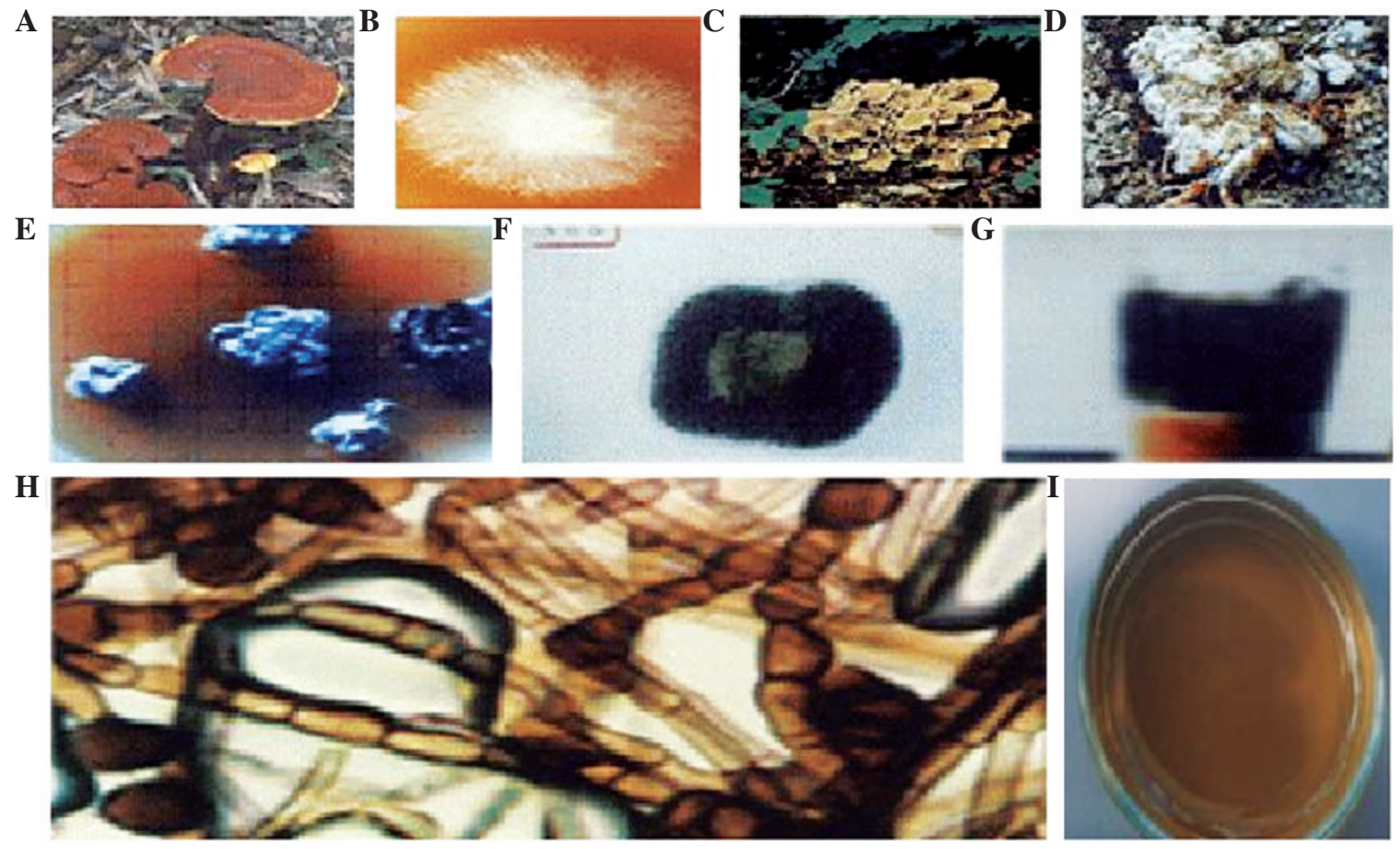

Figure 2. Khz induces apoptosis in transformed cells. (A) Shape of fused fruiting bodies of Ganoderma lucidum. (B) Hyphae isolated from a G. lucidum on a petri dish. (C) G. lucidum. (D) Fused fruiting bodies and hyphae from Polyporus umbellatus. (E) Fusion process of G. lucidum and P. umbellatus. (F) Fused hyphae of G. lucidum and P. umbellatus. (G) Agar of fused fungi. (H) DNA from fused hyphae (Khz). Magnification, x200. (I) Cultivation conditions of Khz. Magnification, $\mathrm{x} 45$.

Western blot analysis. The cells were lysed in extraction buffer (Sigma-Aldrich) containing $31.25 \mathrm{mM}$ Tris-HCl (pH 6.8), $1 \%$ sodium dodecyl sulfate (SDS), $10 \%$ glycerol and $2.5 \%$ mercaptoethanol, and the whole-cell lysates were subjected to separation using 10\% SDS-polyacrylamide gel (Sigma-Aldrich) electrophoresis. The size-fractionated proteins on the gel were then transferred onto a nitrocellulose membrane (GE Healthcare Life Sciences), and the membrane was blocked with $5 \%$ skimmed milk in Tris-buffered saline containing $0.05 \%$ Tween 20 (Sigma-Aldrich), and was incubated with the following primary antibodies: Goat polyclonal anti-caspase-7 (cat. no. sc-22179), anti-caspase-8 (cat. no. sc-6136) and anti-caspase-9 (cat. no. sc-22182), purchased from Santa Cruz Biotechnology, Inc. (Dallas, TX, USA). Following washing once with PBS, the membrane was incubated with a horseradish peroxidase-conjugated mouse anti-goat IgG secondary antibody (cat. no. sc-2354; Santa Cruz Biotechnology, Inc.). The protein band of interest was detected using enhanced chemiluminescence reagents (GE Healthcare Life Sciences, Shanghai, China) (20).

Statistical analysis. Cell viability was expressed as the mean \pm standard deviation. Statistical comparisons were made between the control and treatment groups using Student's $\mathrm{t}$-test. $\mathrm{P}<0.05$ was considered to indicate a statistically significant difference.

\section{Results}

Effects of Khz on cell viability. Khz is the fusion of G. lucidum and P. umbellatus mycelia, as shown in Fig. 2. The aim of the present study was to examine whether Khz causes apoptosis in
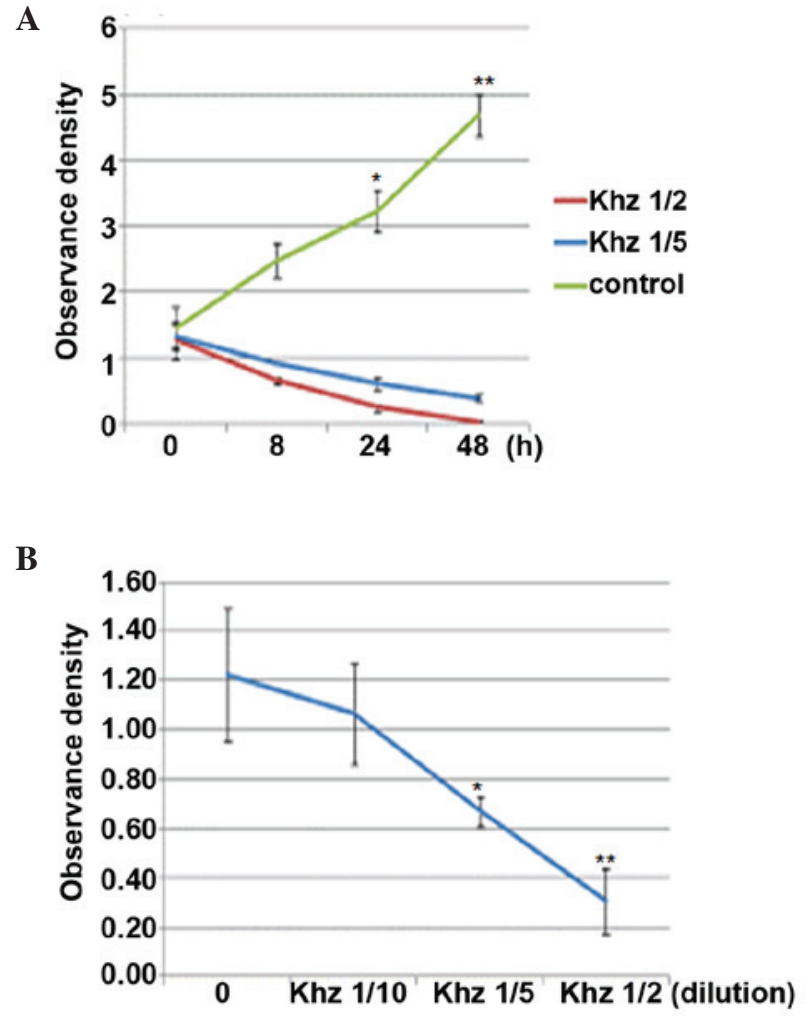

Figure 3. Effect of Khz on the viability of MCF-7 cells, measured using a 3-(4,5-dimethylthiazol-2-yl)-2,5-diphenyltetrazolium bromide assay. (A) MCF-7 cells were incubated with Khz for the indicated time-periods. (B) MCF-7 cells were treated with the indicated concentrations of Khz for $48 \mathrm{~h}$. Each point represents the mean of triplicate samples \pm standard deviation. ${ }^{*} \mathrm{P}<0.05,{ }^{* * *} \mathrm{P}<0.01$ 


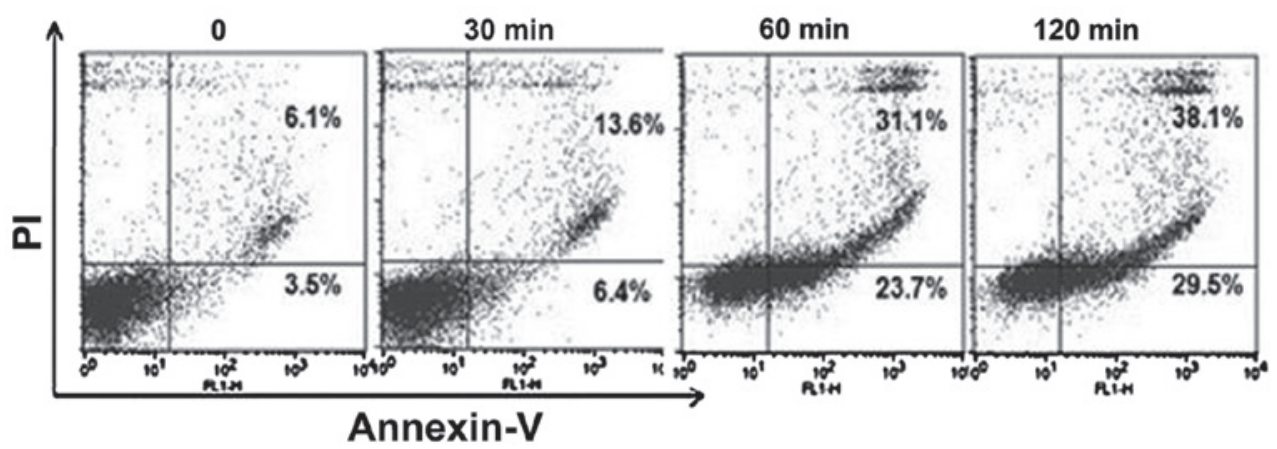

Figure 4. Detection of apoptosis using flow cytometry following annexin V-fluorescein isothiocyanate/PI staining. Lower left quadrant, viable cells (annexin $\mathrm{V} / \mathrm{PI}$ ); lower right quadrant, early apoptotic cells (annexin $\mathrm{V}^{+} / \mathrm{PI}$ ); upper right quadrant, late apoptotic cells (annexin $\mathrm{V}^{+} / \mathrm{PI}^{+}$); upper left quadrant, necrotic cells (annexin $\left.\mathrm{V}^{-} / \mathrm{PI}^{+}\right)$. MCF-7 cells were treated with a 1:2 dilution of $\mathrm{Khz}$, and apoptosis was analyzed after $0.5,1$, and $2 \mathrm{~h}$ by flow cytometry. The cells were exposed to $1 / 2 \mathrm{Khz}$ for $0.5,1$ and $2 \mathrm{~h}$. The numbers in the panels represent the percentage of annexin $\mathrm{V}^{+} / \mathrm{PI}^{-}$and annexin $\mathrm{V}^{+} / \mathrm{PI}^{+}$cells. Data are representative of three independent experiments. PI, propidium iodide.
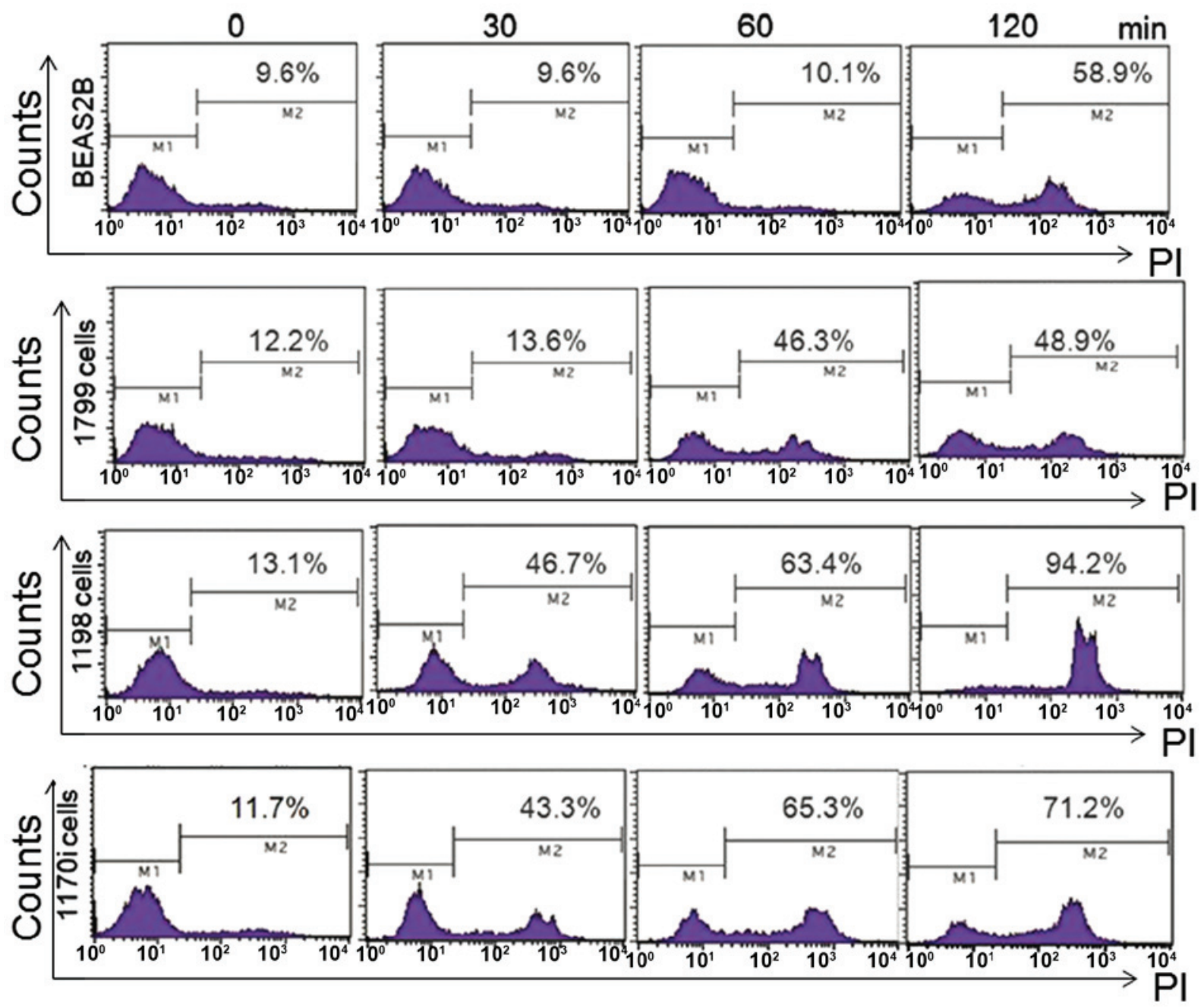

Figure 5. Detection of apoptosis in the transformed cells. BEAS-2B, 1799, 1198 and 1170-I cells were treated with 1/2 Khz for $1 \mathrm{~h}$. Apoptosis was analyzed using propidium iodide staining followed by flow cytometric analysis. The histograms reveal two distinct sub-populations, characterized by low (M1) and high (M2) fluorescence, respectively, corresponding to cells with low and high apoptosis staining.

human cancer cells and, if so, to identify the signaling mechanisms involved. The effects of Khz on MCF-7 cell growth were determined using an MTT assay. As shown in Fig. 3, the MCF-7 cells were treated with different concentrations of Khz for $48 \mathrm{~h}$. Khz markedly inhibited cell growth in a dose- and time-dependent manner. Treatment with $1 / 2 \mathrm{Khz}$ for $24 \mathrm{~h}$ resulted in significant inhibition of cell proliferation.

Effects of Khz on apoptosis. To assess whether Khz induces apoptosis, the MCF-7 cells were double stained with annexin 

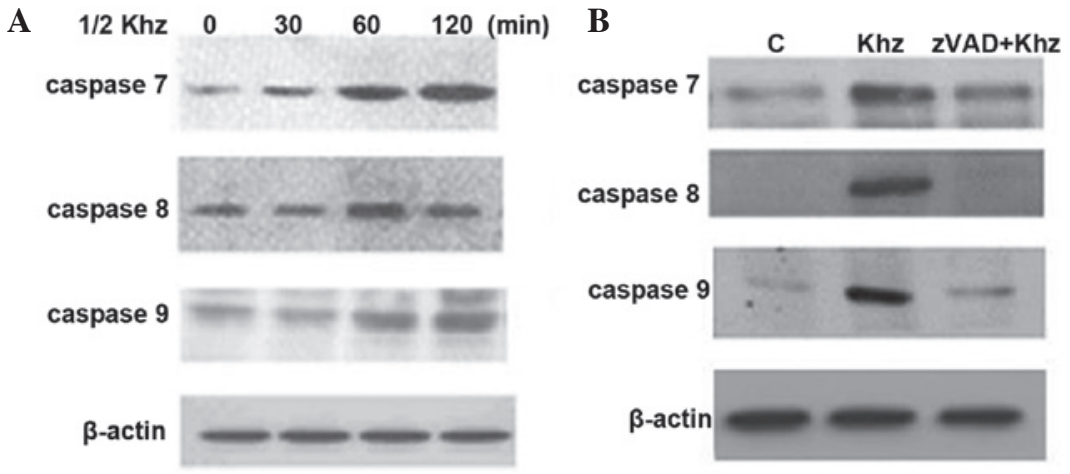

Figure 6. Protein expression levels of caspase 7, 8 and 9 in MCF-7 cells following exposure to Khz. (A) MCF-7 cells were treated with 1/2 Khz, and caspase activation was analyzed using immunoblotting. (B) Cells were pretreated with the pan-caspase inhibitor z-VAD $(20 \mu \mathrm{M})$ for $1 \mathrm{~h}$, followed by treatment with Khz as in (A).

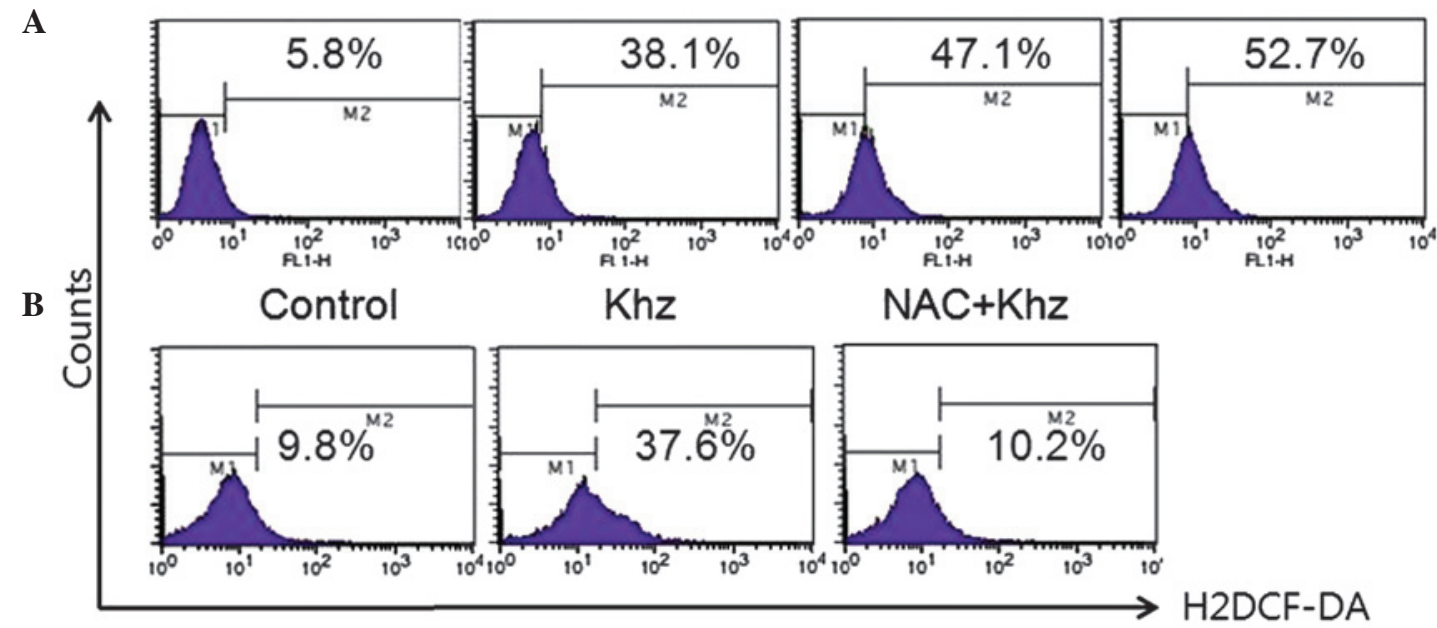

Figure 7. Effect of Khz on the production of ROS in MCF-7 cells. (A) MCF-7 cells were treated with Khz (1/2) for different time-periods ( $0,0.5,1$ and $2 \mathrm{~h}$ ) and the production of ROS was evaluated using flow cytometry. Increasing the duration of incubation with Khz led to increased levels of ROS in the MCF-7 cells. (B) Cells were pretreated with NAC $(1 \mathrm{mM})$ for $1 \mathrm{~h}$ and treated with $1 / 2 \mathrm{Khz}$, following which ROS levels were analyzed. The histograms reveal two distinct sub-populations, characterized by low (M1) and high (M2) fluorescence, respectively, corresponding to cells with low and high ROS staining. ROS, reactive oxygen species; NAC, N-acetyl-L-cysteine; H2DCF-DA, 20,70-dichlorodihydrofluorescein diacetate.

A

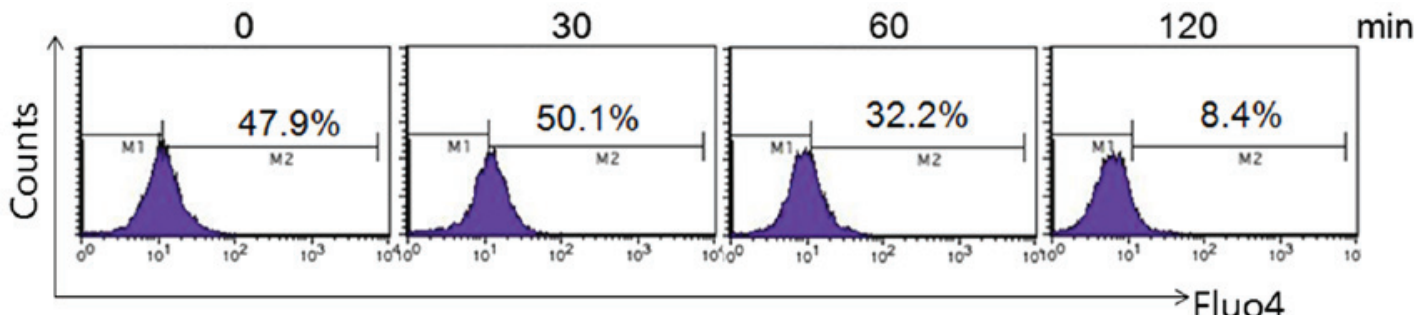

B

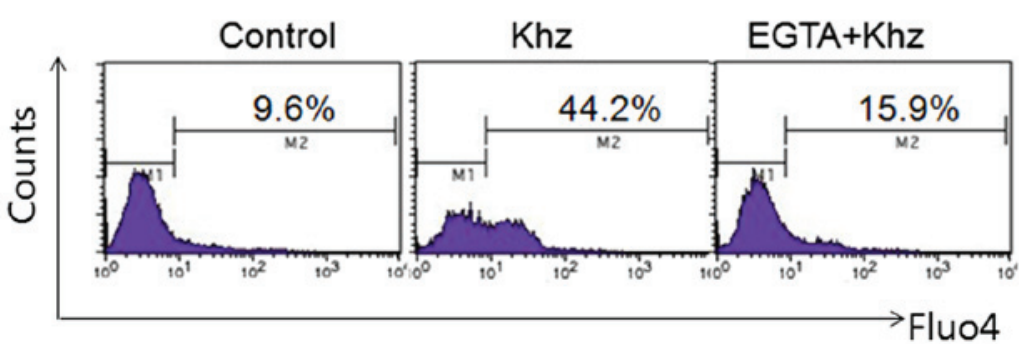

Figure 8. Effect of Khz on the production of $\mathrm{Ca}^{2+}$ in MCF-7 cells. (A) MCF-7 cells were treated with $\mathrm{Khz}(1 / 2)$ for different time-periods $(0,0.5,1$ and $2 \mathrm{~h})$ and intracellular $\mathrm{Ca}^{2+}$ concentrations were measured. The $\mathrm{Ca}^{2+}$ concentrations were significantly different between the Khz-treated group and the control group Khz treatment increased the concentration of $\mathrm{Ca}^{2+}$ in the MCF-7 cells in a time-dependent manner. (B) Cells were pretreated with EGTA (10 $\left.\mu \mathrm{M}\right)$ for $1 \mathrm{~h}$ and treated with $1 / 2 \mathrm{Khz}$. The histograms reveal two distinct sub-populations, characterized by low (M1) and high (M2) fluorescence, respectively, corresponding to cells with low and high $\mathrm{Ca}^{2+}$ staining. EGTA, ethylene glycol tetraacetic acid. 
V-FITC and PI and analyzed using flow cytometry, which is the most sensitive and specific assessment for apoptotic cells in suspension culture. PI was used to differentiate between the apoptotic cells, which maintained plasma membrane integrity (annexin $\mathrm{V}^{+} / \mathrm{PI}^{-}$) and those exhibiting loss-of-membrane integrity (annexin $\mathrm{V}^{+} / \mathrm{PI}^{+}$). Following $\mathrm{Khz}$ treatment at different concentrations for $24 \mathrm{~h}$, the majority of the apoptotic cells were observed in the upper right quadrant (annexin $\mathrm{V}^{+} / \mathrm{PI}^{+}$), indicating that almost all of the apoptotic cells were in the late stages of apoptosis (data not shown). Therefore, to detect cells in early apoptosis, the durations of treatment were reduced. Treatment with $1 / 2 \mathrm{Khz}$ for $1 \mathrm{~h}$ resulted in the presence of early apoptotic cells in the lower right quadrant (annexin $\mathrm{V}^{+} / \mathrm{PI}^{-}$) (Fig. 4). Following treatment for $2 \mathrm{~h}$, the cell population was observed to have shifted between viable cells and those in the early- and late-stages of apoptosis, indicating a time-dependent increase in the percentage of apoptotic MCF-7 cells.

Effect of Khz on transformed cells. An in vitro human lung epithelial carcinogenesis model comprising several cell lines was used in the present study to examine whether the induction of apoptosis by Khz occurred preferentially in transformed cells. BEAS-2B is an immortalized normal human bronchial epithelial cell line, and 1198 and 1170-I are transformed cell lines derived from BEAS-2B cells exposed to beeswax pellets containing cigarette smoke condensate in vivo. The 1799 cell line is a non-transformed line, which is derived from BEAS-2B cells exposed to beeswax alone. Khz induced apoptosis in the transformed 1198 and 1170-I cells, but not in the non-transformed BEAS-2B or 1799 cells (Fig. 5). These data indicated that Khz induced apoptosis preferentially in the cancer cells, which suggested its potential as a cancer therapeutic agent.

Detection of apoptosis-associated proteins in Khz-treated $M C F-7$ cells. Subsequently, the present study analyzed the activation of caspases following Khz treatment to determine whether Khz-induced apoptosis was caspase-dependent. The levels of cleaved caspases 7, 8 and 9 in the MCF-7 cells increased following Khz treatment (Fig. 6A), indicating their activation. In addition, pretreatment of these cells with the pan-caspase inhibitor, z-VAD, resulted in complete inhibition of Khz-induced apoptosis (Fig. 6B). These data demonstrated that $\mathrm{Khz}$ induced caspase-dependent apoptosis.

Effects of Khz on ROS production in MCF-7 cells. As oxidative stress is involved in apoptosis induced by a variety of stresses, the production of ROS following Khz treatment was analyzed in the present study. As shown in Fig. 7A, ROS levels in the MCF-7 cells increased by 22.3 and $65.1 \%$ in response to $\mathrm{Khz}$ treatment for 30 and $60 \mathrm{~min}$, respectively, compared with the untreated cells (7.1\%). Co-treatment with the ROS scavenger, N-acetyl-L-cysteine, prevented ROS formation (Fig. 7B). These results suggested that $\mathrm{Khz}$ induced apoptosis by generating ROS.

Effects of $\mathrm{Khz}$ on $\left[\mathrm{Ca}^{2+}\right]_{i}$ production in $\mathrm{MCF}-7$ cells. Assessment of the effect of $\mathrm{Khz}$ on intracellular calcium levels revealed that $\mathrm{Khz}$ evoked an increase in $\left[\mathrm{Ca}^{2+}\right]_{i}$ in the MCF-7 cells (Fig. 8A). Treatment of the MCF-7 cells with Khz induced an increase in the percentage of calcium, between 33.6 and 72.2 , and $86.2 \%$ following treatment for 0.5 and $2 \mathrm{~h}$, respectively, compared with the untreated cells (7.1\%). This Khz-induced increase in $\left[\mathrm{Ca}^{2+}\right]_{\mathrm{i}}$ was inhibited by the extracellular $\mathrm{Ca}^{2+}$ chelator, ethylene glycol tetraacetic acid. These results suggested that $\mathrm{Khz}$ triggered apoptosis by increasing intracellular $\mathrm{Ca}^{2+}$ (Fig. 8B).

\section{Discussion}

In a previous study, it was demonstrated that tanshinone IIA induces apoptosis in A549 human lung cancer cells through the induction of ROS and by decreasing mitochondrial membrane potential (21). In addition, our previous study demonstrated that Khz induces apoptosis by increasing intracellular calcium levels and activating c-Jun N-terminal kinase and NADPH oxidase-dependent generation of ROS (22). These findings suggested that Khz induces apoptosis in A549 human lung cancer cells by generating reactive oxygen species and decreasing the mitochondrial membrane potential (23). In addition, it has been suggested that $\mathrm{Khz}$ induces apoptosis in human colon carcinoma HCT116 cells, accompanied by an increase in ROS, the activation of caspase 3 and increased intracellular $\mathrm{Ca}^{2+}$ (24). In addition, our previous study demonstrated that crude polysaccharide extract obtained from the fusion of G. lucidum and P. umbellatus mycelia induces apoptosis by increasing intracellular $\mathrm{Ca}^{2+}$ levels and activating the P38 and NADPH oxidase-dependent generation of reactive oxygen species in SNU-1 cells (25). In the present study, fusion of G. lucidum and P. umbellatus mycelium was perofmeed and used to treat MCF-7 cells. The results demonstrated that $\mathrm{Khz}$ inhibited cell proliferation and induced apoptosis in the MCF-7 breast cancer cells (Fig. 3). In addition, the mechanism by which Khz induces apoptosis in cancer cells was investigated (Fig. 4). Khz induced apoptosis preferentially in transformed cells, with a minimal effect on non-transformed cells, suggesting it may offer potential as a cancer therapeutic agent. Oxidative stress is associated with apoptotic and non-apoptotic cell death, although pro-oxidative conditions are not a prerequisite for apoptosis (Fig. 5). Assessment of the activation statuses of caspases 7,8 and 9 revealed that the levels of cleaved caspases were significantly increased in the cells treated with $\mathrm{Khz}$ (Fig. 6). Taken together, these results suggested that $\mathrm{Khz}$ induced apoptosis by activating caspases, and that the induction of apoptosis by Khz required ROS generation (Fig. 7). It is widely accepted that calcium signaling is important in apoptosis. The present study demonstrated that there was an increase in $\left[\mathrm{Ca}^{2+}\right]_{i}$ in the MCF-7 cells in response to Khz treatment (Fig. 8).

The pro-apoptotic and cytotoxic effects of Khz demonstrated in the present study suggest it has potential as a chemotherapeutic agent for the treatment of human breast cancer. Further investigations of the effects of Khz, including in vivo investigations, are necessary to determine its potential for clinical use.

\section{Acknowledgements}

This study was supported by Mr. Young Lye Chae, chief executive officer, at Brain Group Co., Ltd., Pharmacology and Drug 
Development, Korean Institute of Science and Management Career College (Seoul, Korea; grant no. BRG815-1386).

\section{References}

1. Lin ZB and Zhang HN: Anti-tumor and immunoregulatory activities of Ganoderma lucidum and its possible mechanisms Acta Pharmacol Sin 25: 1387-1395, 2004.

2. Sandodiya BS, Thakur GS, Baqhel RK, Prasad GB and Bisen PS: Ganoderma lucidum: A potent pharmacological macrofungus. Curr Pharm Biotechnol 10: 717-742, 2009.

3. Gao Y, Gao H, Chan E, Tang W, Xu A, Yang H, Huang M, Lan J, Li X, Duan W, et al: Antitumor activity and underlying mechanisms of ganopoly, the refined polysaccarides extracted from Ganoderma lucidum, in mice. Immunol Invest 34: 171-198, 2005.

4. Yue GG, Fung KP, Tse GM, Leung PC and Lau CB: Comparative studies of various Ganoderma species and their different parts with regard to antitumor and immunomodulating activities in vitro. J Altern Complement Med 12: 777-789, 2006.

5. IIIana-Esteban C: The fungus maitake (Grifola frondosa) and its therapeutic potential. Rev Iberoam Micol 25: 141-144, 2008 (In Spanish).

6. Jang KJ, Han MH, Lee BH, Kim BW, Kim CH, Yoon HM and Choi YH: Induction of apoptosis by ethanol extracts of Ganoderma lucidum in human gastric carcinoma cells J Acupunct Meridian Stud 3: 24-31, 2010.

7. Yue QX, Song XY, Ma C, Feng LX, Guan SH, Wu WY, Yang M, Jiang BH, Liu X, Cui YJ and Guo DA: Effects of triterpenes from Ganoderma lucidum on protein expression profile of HeLa cells. Phytomedicine 17: 606-613, 2010.

8. Zhao S, Ye G, Fu G, Cheng JX, Yang BB and Peng C: Ganoderma lucidum exerts anti-tumor effects on ovarian cancer cells and enhances their sensitivity to cisplatin. Int J Oncol 38 : 1319-1327, 2011.

9. Liu RM and Zhong JJ: Ganoderic acid Mf and S induce mitochondria mediated apoptosis in human cervical carcinoma HeLa cells. Phytomedicine 15: 349-355, 2011.

10. Li L, Li T, Wang XJ, Xu JP and Wang SG: Effects of Ganoderma lucidum spores on HepG2 cells proliferation and growth cycle. Zhong Yao Cai 31: 1514-1518, 2008 (In Chinese).

11. Zhao YY, Chao X, Zhang Y, Lin RC and Sun WJ: Cytotoxic steroids from Polyporus umbellatus. Planta Med 76: 1755-1758, 2010.

12. Tang W, Liu JW, Zhao WM, Wei DZ and Zhong JJ: Ganoderic acid T from Ganoderma lucidum mycelia induces mitochondria mediated apoptosis in lung cancer cells. Life Sci 80: 205-211, 2006.

13. Liang ZE, Yi YJ, Guo YT, Wang RC, Hu QL and Xiong XY: Inhibition of migration and induction of apoptosis in LoVo human colon cancer cells by polysaccharides from Ganoderma lucidum. Mol Med Rep 12: 7629-7636, 2015.
14. Ruan W, Wei Y and Popovich DG: Distinct responses of cytotoxic Ganoderma lucidum triterpenoids in human carcinoma cells. Phytother Res 29: 1744-1752, 2015.

15. Sun Z, Huang K, Fu X, Zhou Z, Cui Y and Li H: A chemically sulfated polysaccharide derived from Ganoderma lucidum induces mitochondrial-mediated apoptosis in human osteosarcoma MG63 cells. Tumour Biol 35: 9919-9926, 2014.

16. Kim JE, Koo KH, Kim YH, Sohn J and Park YG: Identification of potential lung cancer biomarkers using an in vitro carcinogenesis model. Exp Mol Med 40: 709-720, 2008.

17. Palombo JD, Ganguly A, Bistrian BR and Menard MP: The antiproliferative effects of biologically active isomers of conjugated linoleic acid on human colorectal and prostatic cancer cells. Cancer Lett 177: 163-172, 2002.

18. Klein-Szanto AJ, Iizasa T, Momiki S, Garcia-Palazzo I, Caamano J, Metcalf R, Welsh J and Harris CC: A tobacco-specific $\mathrm{N}$-nitrosamine or cigarette smoke condensate causes neoplastic transformation of xenotransplanted human bronchial epithelial cells. Proc Natl Acad Sci USA 89: 6693-6697, 1992.

19. Kang KS, Wang P, Yamabe N, Fukui M, Jay T and Zhu BT: Docosahexaenoic acid induces apoptosis in MCF-7 cells in vitro and in vivo via reactive oxygen species formation and caspase 8 activation. PLoS One 5: e10296, 2010.

20. Yu SJ, Kim HS, Cho SW and Sohn J: IL-4 inhibits proliferation of renal carcinoma cells by increasing the expression of p21WAF1 and IRF-1. Exp Mol Med 36: 372-379, 2004.

21. Yan Z, Yang R, Jiang Y, Yang Z, Yang J, Zhao Q and Lu Y: Induction of apoptosis in human promyelocytic leukemia HL60 cells by panaxynol and panaxydol. Molecules 16: 5561-5573, 2011.

22. Kim TH, Kim JS, Kim ZH, Huang RB and Wang RS: Khz (fusion of Ganoderma lucidum and Polyporus umbellatus mycelia) induces apoptosis by increasing intracellular calcium levels and activating JNK and NADPH oxidase-dependent generation of reactive oxygen species. PLoS One 7: e46208, 2012.

23. Kim TH, Kim JS, Kim ZH, Huang RB and Wang RS: Khz (Fusion of Ganoderma lucidum and Polyporus umbellatus Mycelia) induces apoptosis in A549 human lung cancer cells by generating reactive oxygen species and decreasing the Mitochondrial membrane potential. Food Sci Biotechnol 23: 859-864, 2014

24. Kim TH, Kim JS, Kim ZH, Huang RB, Chae YL and Wang RS: Khz (Fusion product of Ganoderma lucidum and Polyporus umbellatus mycelia) induces apoptosis in human colon carcinoma HCT116 cells, accompanied by an increase in reactive oxygen species, activation of caspase 3 and increased intracellular $\mathrm{Ca}^{2+}$ J Med Food 18: 332-336, 2015.

25. Kim TH, Kim JS, Kim ZH, Huang RB, Chae YL and Wang RS: Khz-cp (crude polysaccharide extract obtained from the fusion of Ganoderma lucidum and Polyporus umbellatus mycelia) induces apoptosis by increasing intracellular calcium levels and activating P38 and NADPH oxidase-dependent generation of reactive oxygen species in SNU-1 cells. BMC Complement Altern Med 14: 236, 2014. 